\title{
Effect of Sildenafil Citrate and Estradiol Valerate on Endometrial Characteristics in Ovulation-induced Cycle in Women with Dysovulatory Infertility
}

\author{
Shailza Vardhan ${ }^{1}$, Poonam Yadav ${ }^{2}$, Rachana Agarwal ${ }^{3}$, Ruchika Garg ${ }^{4}$, Urvashi Verma ${ }^{5}$, Mohita Pengoria ${ }^{6}$
}

\begin{abstract}
Objective: The objective of this study was to study the effect of sildenafil citrate and estradiol valerate on endometrial thickness, blood flow, and pregnancy outcomes in women with dysovulatory infertility.

Materials and methods: It is a comparative prospective study, including 80 women with primary or secondary dysovulatory infertility. Women with thin endometrium were randomly distributed in two groups. In group I (estradiol group), 40 women were included and given estradiol valerate tablets orally by the step-up method, and in group II (sildenafil plus estradiol group), 40 women were included and given sildenafil citrate tablets orally $25 \mathrm{mg}$ TDS daily in addition to the estradiol valerate tablets as per above the step-up method from day 1 of the cycle until 12th day. Patients were reevaluated by transvaginal sonography (TVS) from day 10th until documentation of ovulation for endometrial thickness and pattern with number and size of graffian follicle.

Results: Mean endometrial thickness posttreatment on day 14 th was $9.0175 \pm 2.58 \mathrm{~mm}$ in group I and $9.375 \pm 1.989 \mathrm{~mm}$ in group II. Only $45 \%$ in group I had vascularity up to zone 3 , whereas $62.5 \%$ patients in group II had zone 3 endometrial vascularity $(p$ value $<0.05)$. Clinical pregnancy rate in group I and group II was $22.5 \%$ and $35 \%$, respectively ( $p$ value $<0.05$ ).

Conclusion: Both oral estradiol valerate and sildenafil citrate significantly improve endometrial thickness, vascularity, and echogenicity. When compared to estradiol alone (which increases endometrial thickness and echogenicity) but the addition of sildenafil citrate improves endometrial blood flow.

Keywords: Endometrial thickness, Estradiol valerate, Infertility, Sildenafil citrate.

Journal of South Asian Federation of Obstetrics and Gynaecology (2019): 10.5005/jp-journals-10006-1687
\end{abstract}

\section{INTRODUCTION}

According to WHO and ICMRT, infertility is a disease of reproductive system defined by the failure to achieve clinical pregnancy after 1 year or more of regular, unprotected sexual intercourse. ${ }^{1}$ Endometrial factors and implantation failure are the known cause of infertility and there is a good correlation between endometrial thickness and the prevalence of conception. ${ }^{2}$ An endometrial thickness $<7 \mathrm{~mm}$ is a reliable sign of suboptimal implantation potential. ${ }^{3}$ Endometrial thickness is dependent on several factors, including reproductive age, phase of menstrual cycle, estrogen and progesterone concentration, and endometrial hormone receptor density. ${ }^{4}$ Multiple treatment modalities have been studied in improving thin endometium such as aspirin, heparin, L-arginine, vitamin E, nitrates, estrogen, pentoxiphylline, tocopherol, and intrauterine infusion of growth factors such as G-CSF and stem cell therapy.

Sildenafil citrate is a potent and selective inhibitor of cGMPspecific phosphodiesterase 5 (PDE-5), hence augment the vasodilatory effect of nitric oxide by preventing the degradation of cGMP, which leads to increased uterine blood flow and thicker endometrium. ${ }^{5}$ Alternatively, sildenafil may have an effect on vasoactive cytokines that regulate endometrial development or implantation. Sildenafil increases uterine receptivity by the development of spiral arteries and by increasing the uterine arterial blood flow. ${ }^{6}$

The effect of estrogen on endometrium occurs not via direct or regional transmission from the neighboring ovaries but rather through the systemic circulation.

This study focused on endometrial thinning as a cause of implantation failure, and aim of this study was to estimate the effect
${ }^{1-6}$ Department of Obstetrics and Gynaecology, Sarojini Naidu Medical College, Agra, Uttar Pradesh, India

Corresponding Author: Shailza Vardhan, Department of Obstetrics and Gynaecology, Sarojini Naidu Medical College, Agra, Uttar Pradesh, India, Phone: +91 7818803747, e-mail: shailzavardhan@gmail.com

How to cite this article: Vardhan S, Yadav P, Agarwal R, et al. Effect of Sildenafil Citrate and Estradiol Valerate on Endometrial Characteristics in Ovulation-induced Cycle in Women with Dysovulatory Infertility. J South Asian Feder Obst Gynae 2019;11(3):164-166.

Source of support: Nil

Conflict of interest: None

of sildenafil citrate on ultrasonographic endometrial thickness, pattern, and vascularity.

\section{Materials and Methods}

The study was conducted on patients attending infertility OPD at the Department of Obstetrics and Gynaecology, Sarojini Naidu Medical College, Agra over a period of 2 years and the ethical clearance was taken for the same from the ethical committee of the college.

\section{Inclusion Criteria}

Women less than 35 years of age with primary or secondary infertility with patent fallopian tubes, with normal husband semenogram, and without any organic pelvic pathology; patient 
with an endometrial thickness of $<7 \mathrm{~mm}$ on the day of ovulation or day 14 in clomiphene-induced cycle.

\section{Exclusion Criteria}

Congenital uterine anomaly, acquired deformities of uterus (Asherman syndrome), tubal factors of infertility, sensitivity to sildenafil citrate, contraindication for estrogen treatment (history of stroke, deep venous thrombosis, benign liver disease), and male factor infertility.

\section{Sample Size}

A total of 500 patients attending infertility OPD were screened and 200 patients were found with dysovulatory causes. Of these, 150 patients were selected for the study, and all these 150 patients after consent and fulfilling the inclusion criteria underwent day 2 basal scan and then were prescribed clomiphene citrate $50 \mathrm{mg}$ once daily for five days from day 2 . From day 10 transvaginal scans were done for folliculometry on alternate days till the documentation of ovulation. An estimated 80 patients were found to have endometrial thickness of $<7 \mathrm{~mm}$ on the day of ovulation and these patients were randomly divided into two groups and in the next cycle, the following regimens were prescribed to them along with clomiphene citrate $50 \mathrm{mg}$ once daily for five days from day 2 .

\section{Group I (Estradiol Group)}

Totally, 40 patients were included and given estradiol valerate tablets orally by the step-up method: from the first day to the fourth day, $2 \mathrm{mg}$ estradiol valerate tablets, and from the 5th to the 8th day, $4 \mathrm{mg}$ estradiol tablets, and from the 9th to the 12th day of the menstrual cycle, $6 \mathrm{mg}$ estradiol valerate were given daily.

\section{Group II (Sildenafil Plus Estradiol Group)}

An estimated 40 patients were included and given sildenafil citrate tablets orally $25 \mathrm{mg}$ TDS daily in addition to the estradiol valerate tablets as per the above step-up method from day 1 of the cycle until the 12th day.

All these patients were reevaluated on the 10th day by TVS on alternate day till the documentation of ovulation for endometrial characteristics (i.e., endometrial thickness, endometrial vascularity, endometrial echogenicity, and number and size of graffian follicle and positive pregnancy test). Patients were followed up until detection of fetal heart rate in ultrasonography.

\section{Results}

The mean age in group I and group II was $28.4 \pm 4.6$ and $25.8 \pm 5.4$ years, respectively. Only 34 of 40 patients in group I and 32 of 40 patients in group II had primary infertility, whereas 6 of 40 patients in group I and 8 of 40 patients in group II had secondary infertility. The mean duration of infertility in group I and group II was 3.6 years and 4.2 years, respectively. None of the patient's characteristics were statistically significant in both groups (Table 1). In group I, 25 patients had endometrial thickness in the range of $7-10 \mathrm{~mm}$; in group II, 29 patients had endometrial thickness in the range of 7-10 $\mathrm{mm}$ (Table 2). In both groups, there is significant improvement in endometrial thickness when compared to pretreatment endometrial thickness. In group I, the pretreatment endometrial thickness was $5.20 \pm 0.80 \mathrm{~mm}$, which increased to $9.0175 \pm$ $2.58 \mathrm{~mm}$ post treatment; similarly in group II, the pretreatment endometrial thickness was $5.56 \pm 0.58 \mathrm{~mm}$, which increased to $9.375 \pm 1.989 \mathrm{~mm}$ post treatment ( $p$ value $<0.05$ ) (Table 2 ).
Table 1: Patients' characteristics

\begin{tabular}{lll}
\hline & Group I $(n=40)$ & Group II $(n=40)$ \\
\hline Mean age (in years) & $28.4 \pm 4.6$ & $25.8 \pm 5.4$ \\
Primary infertility & 34 & 32 \\
Secondary infertility & 06 & 08 \\
Mean BMI $\left(\mathrm{kg} / \mathrm{m}^{2}\right)$ & 23.3 & 22.7 \\
Mean duration of & 3.6 & 4.1 \\
infertility (in years) & & \\
\hline
\end{tabular}

Table 2: Endometrial thickness and endometrial pattern in both groups on the day of ovulation

\begin{tabular}{|c|c|c|c|c|}
\hline \multirow{2}{*}{$\begin{array}{l}\text { Endometrial thickness (in } \mathrm{mm} \text { ) on } \\
\text { day } 14\end{array}$} & \multicolumn{2}{|c|}{ Group I } & \multicolumn{2}{|c|}{ Group II } \\
\hline & No. & $\%$ & No. & $\%$ \\
\hline$<7 \mathrm{~mm}$ & 4 & 10 & 1 & 2.5 \\
\hline $7-10 \mathrm{~mm}$ & 25 & 62.5 & 29 & 72.5 \\
\hline $10.1-15 \mathrm{~mm}$ & 11 & 27.5 & 10 & 25 \\
\hline $\begin{array}{l}\text { Pretreatment mean endometrial } \\
\text { thickness (in } \mathrm{mm} \text { ) }\end{array}$ & \multicolumn{2}{|c|}{$5.20 \pm 0.80$} & \multicolumn{2}{|c|}{$5.56 \pm 0.58$} \\
\hline $\begin{array}{l}\text { Posttreatment mean endometrial } \\
\text { thickness (in } \mathrm{mm} \text { ) }\end{array}$ & \multicolumn{2}{|c|}{$9.0175 \pm 2.58$} & \multicolumn{2}{|c|}{$9.375 \pm 1.989$} \\
\hline Endometrial pattern (trilaminar) & \multicolumn{2}{|c|}{27 (67.5\%) } & \multicolumn{2}{|c|}{31 (77.5\%) } \\
\hline
\end{tabular}

$p$ value (pre- and posttreatment endometrial thickness) $<0.05$ statistically significant

Also, 27 cases in group I and 31 cases in group II developed a trilaminar pattern of endometrium (Table 2). In both groups, a maximum number of cases had vascularity in zone III: 18 patients $(45 \%)$ in group I and 25 patients $(62.5 \%)$ in group II ( $p$ value $<0.05$ ) (Table 3). Hyperechogenic endometrium is seen in 22 patients $(55 \%)$ in group I and 33patients (82.5\%) in group II (Table 3). The mean number of follicles in group I was $2.20 \pm 0.7$ and in group II was $2.58 \pm 1.05$, and the mean follicular size in group I and group II was $17 \pm 2.2 \mathrm{~mm}$ and $18.4 \pm 2.6 \mathrm{~mm}$, respectively (Table 4). Clinical pregnancy rate in group I and group II was $22.5 \%$ and $35 \%$, respectively. Thus, a significant improvement in pregnancy rate ( $p$ value $<0.05$ ) was also observed in patients with a poor endometrium when a combinatorial dose of sildenafil and estradiol was given when compared to estradol alone (Table 5).

\section{Discussion}

Dysovulatory infertility accounts for approximately $30-40 \%$ of all cases of female infertility, but is generally easily diagnosed and is the most treatable cause of female infertility. Clomiphene citrate is the first-line treatment for induction of ovulation. Despite good results reported with clomiphene for induction of ovulation, a large proportion of females do not achieve pregnancy and the cause may be attributed to failure of implantation. Implantation failure occurs in female with a poor endometrium in terms of thickness and its vascularity.

Despite various treatment modalities available for the treatment of infertility, thin endometrium still remains a challenge for gynecologists. Therefore, the study was conducted with an aim to evaluate the effect of estradiol valerate and sildenafil citrate in females with a thin endometrium as a cause of implantation failure in patients with dysovulatory infertility.

The mean endometrial thickness pretreatment in group I was $5.20 \pm 0.80 \mathrm{~mm}$ and in group II was $5.56 \pm 0.58 \mathrm{~mm}$, which 
Table 3: Endometrial vascularity and echogenicity in both groups

\begin{tabular}{lrrrrr}
\hline & \multicolumn{2}{c}{ Group I } & & \multicolumn{2}{c}{ Group II } \\
\cline { 2 - 3 } & No. & $\%$ & & No. & $\%$ \\
\hline A. Vascularity & 6 & 15 & & 5 & 12.5 \\
$\quad$ Zone 1 & 16 & 40 & & 10 & 25 \\
$\quad$ Zone 2 & 18 & 45 & & 25 & 62.5 \\
$\quad$ Zone 3 & & & & & \\
B. Echogenicity & 4 & 10 & & 1 & 2.5 \\
$\quad$ Hypoechogenic & 14 & 35 & & 6 & 15 \\
Isoechogenic & 22 & 55 & & 33 & 82.5 \\
\hline Hyperechogenic & & & & &
\end{tabular}

Zone 1: subendometrial zone

Zone 2: outer hyperechogenic zone

Zone 3: inner hypoechogenic zone

$p$ value (zone 3 vascularity) $<0.05$ statistically significant

$p$ value (hyperechogenic endometrium) $<0.05$ statistically significant

Table 4: Number and size of recruited follicles in both groups

\begin{tabular}{lcl}
\hline & Group I & Group II \\
\hline Mean number of follicles & $2.20 \pm 0.7$ & $2.58 \pm 1.05$ \\
Mean follicular size (in mm) & $17 \pm 2.2$ & $18.4 \pm 2.6$ \\
\hline
\end{tabular}

Table 5: Pregnancy rate in both groups

\begin{tabular}{lcclll}
\hline & \multicolumn{2}{c}{ Group I } & & \multicolumn{2}{c}{ Group II } \\
\cline { 2 - 3 } \cline { 5 - 6 } & No. & $\%$ & & No. & $\%$ \\
\hline Urine pregnancy test positive & 10 & 25 & & 16 & 40 \\
FHS in USG & 9 & 22.5 & & 14 & 35 \\
\hline
\end{tabular}

$p$ value $<0.05$ statistically significant

significantly improves to $9.0175 \pm 2.58 \mathrm{~mm}$ and $9.375 \pm 1.989$ $\mathrm{mm}$ in group I and group II, respectively ( $p$ value $<0.05$ ) (Table 2 ). The results were compared to those of the previous studies. In a prospective study done by Firouzabadi et al., $50 \mathrm{mg}$ sildenafil was used orally, starting from 1st day till 45-72 hours prior to the embryo transfer. Endometrial thickness and triple-line pattern was found to be significantly higher with sildenafil and estradiol valerate when compared to estradiol alone. Clinical pregnancy rate was higher but not significant. ${ }^{7}$

Takasaki et al. used $100 \mathrm{mg}$ sildenafil intravaginally starting the first day of cycle till day of ovulation and $92 \%$ patients showed improvement in endometrial thickness. ${ }^{8}$ Jimenez et al. used oral estradiol $2 \mathrm{mg}$ thrice a day from day one for 12 days. They reported appropriate development of endometrium in $67 \%$ patients. ${ }^{9}$ Although most of the studies have been published comparing the role of estradiol and sildenafil alone with patients' previous cycle taken as control but the present study is unique in its own kind, taking both estradiol and sildenafil to improve endometrial characteristics in patients with thin endometrium and thereby increasing clinical pregnancy rate.

\section{Conclusion}

In the present study it was shown that a combined use of oral estradiol valerate and sildenafil citrate significantly improves endometrial thickness, vascularity, and echogenicity, thus, improving endometrial receptivity. When compared to estradiol alone, which increases endometrial thickness and echogenicity but the addition of sildenafil citrate improves endometrial blood flow, thus enabling the estrogen for proliferation of endometrial lining, which is the cornerstone of achieving better pregnancy rate and outcome. However, large randomized control trials are required to reach more confirmatory results.

\section{References}

1. Zegar-Hoshschild F, Adamson GD, Demouzou J, et al. The International committee for monitoring assisted reproductive technology (ICMRT) and World Health Organization (WHO) revised glossary an ART technology 2009. Hum Reprod 2009;24(11):2683-2687. DOI: 10.1093/ humrep/dep343.

2. Gonen Y, Casper RF. Prediction of implantation by sonographic appearance of the endometrium during controlled ovarian stimulation for in vitro fertilization. J In Vitro Fert Embryo Transf 1990;7:146. DOI: 10.1007/BF01135678.

3. Sher G, Fisch JD. Vaginal sildenafil citrate (viagra) a preliminary report of a novel method to improve uterine artery blood flow and endometrial development in patients undergoing IVF. Hum Reprod 2000;15:806-809.

4. Xhang $\mathrm{X}$, Chen $\mathrm{CH}$, Confino $\mathrm{E}$, et al. Increased endometrial thickness is associated with improved treatment outcome for selected patients undergoing in vitro fertilization - embryo transfer. Fertil Steril 2005;83:336-340. DOI: 10.1016/j.fertnstert.2004.09.020.

5. Fahmy AA, El-sokkary M, Sayed S. The value of oral sildenafil in the treatment of female infertility: A randomized clinical trial. Life Sci J 2015;12:78-82.

6. Dehghani Firouzabadi R, Davar R, Hojjat F, et al. Effect of sildenafil citrate on endometrial preparation and outcome of frozen thawed embryo transfer cycle: A randomized clinical trial. Iran J Reprod Med 2013;11:151-158.

7. Firouzabadi DR, Davar R, Hojjat F, et al. Effect of sildenafil citrate on endometrial preparation and outcome of frozen - thawed embryo transfer cycles: a randomized clinical trial. Iran J Reprod Med 2013;11(2):151-158.

8. Takasaki A, Tamura H, Mia I, et al. Endometrial growth and uterine blood flow: a pilot study for improving endometrial thickness in the patients with a thin endometrium. Fertil Steril 2010;93(6):1851-1858. DOI: 10.1016/j.fertnstert.2008.12.062.

9. Jimenez PT, Schon SB, Odem RR, et al. A retrospective cross-sectional study: fresh cycle endometrial thickness is a sensitive predictor of inadequate endometrial thickness in frozen embryo transfer cycles. Reprod Biol Endocrinol 2013;11:35. DOI: 10.1186/1477-7827-11-35. 